\title{
Penerapan Metode PROMETHEE II Pada Pemilihan Situs Travel Berdasarkan Konsumen
}

\author{
Dinda Nabila Batubara ${ }^{[1]}$, Dini Rizky Sitorus $\mathrm{P}^{[2]}$, Agus Perdana Windarto ${ }^{[3]}$ \\ STIKOM Tunas Bangsa, Pematangsiantar, Indonesia ${ }^{[1],[2],[3]}$ \\ Jl. Jenderal Sudirman Blok A No.1/2/3 \\ dindanabilabatubara@gmail.com ${ }^{[1]}$, dinirizkysp@gmail.com ${ }^{[2]}$, agusperdana@amiktunasbangsa.ac.id ${ }^{[3]}$
}

\begin{abstract}
Abstrak-Situs Travel merupakan tempat bagi Travel Agent untuk menawarkan jasa-jasa atau paket wisata mereka pada website berbasis online dan dengan situs travel, pelanggan tidak kesulitan dalam memesan paket wisata, mereka cukup memesan melalui smartphone tanpa harus ke biro travel agent. Banyaknya situs travel yang ada membuat para pelanggan bingung dan kesulitan dalam memilih situs travel yang tepat. Penelitian ini bertujuan untuk menganalisa situs travel yang tepat bagi konsumen dengan menerapkan metode PROMETHEE II. Data penelitian diperoleh dengan melakukan wawancara dan penyebaran angket secara random kepada 250 responden. Kriteria penilaian yang digunakan sebanyak 6: penilaian harga (C1), Pelayanan (C2), Interface (C3), Keamanan (C4), Promosi (C5), Sistem Pembayaran (C6) dan alternatif situs travel yang digunakan sebanyak 4: Traveloka (A1), Tiket.com (A2), Trivago (A3), Pegi-Pegi (A4). Hasil analisa menyebutkan bahwa PROMETHEE II dapat diterapkan dalam memilih situs travel dengan alternatif Tiket.com (A2) (net flow= 0.13) sebagai alternatif pertama dan alternatif pegi-pegi (A4) (net flow $=0.10$ ) sebagai alternatif kedua.
\end{abstract}

Kata Kunci- Situs Travel; Sistem Pendukung Keputusan; PROMETHEE II.

\section{PENDAhUlUAN}

Travelling bukan lagi hal mewah, saat ini Travelling telah menjadi gaya hidup. Ada yang menjadikan kegiatan travelling sebagai hobi atau juga program wajib pada sebuah komunitas atau organisasi saat menjelang libur panjang. Travelling memang bukan kegiatan yang murah apalagi tujuannya ke destinasi yang jauh diluar pulau atau diluar negeri. Namun sekarang sudah ada situs travel yang dapat mempermudah seseorang untuk travelling ketempat yang diinginkan. Situs Travel adalah wadah atau tempat bagi Travel Agent untuk menawarkan jasa-jasa atau paket wisata mereka pada website berbasis online, dan dengan adanya situs travel costumer/pelanggan tidak kesulitan dalam memesan paket wisata, cukup memesan melalui internet tanpa harus ke biro travel untuk memesan paket wisata.
Berkembangnya teknologi di era revolusi 4.0, menjadikan transaski secara online adalah suatu kebutuhan bagi saat ini. Salah satunya kehadiran situ travel. Dalam hal ini konsumen sangat diuntungkan dengan kehadiran situs travel yang menawarkan segudang promosi dan kelebihan yang tentunya hal itu dapat diakses dengan cepat menggunakan smartphone. Penelitian ini dilakukan di kota pematangsiantar. Tujuan penelitian ini adalah menganalisa pemilihan situs travel yang tepat berdasarkan pilihan konsumen. Tentunya banyak cabang ilmu komputer yang dapat menganalisa permasalah tersebut Diantaranya adalah datamining [1]-[3][4], [5], sistem pendukung keputusan [6]-[12], logika fuzzy [13]-[16], sistem pakar [17]-[19], jaringan saraf tiruan [1], [20]-[22] dan lainlain[23]. Setiap cabang ilmu tersebut memiliki kelebihan dan kelemahan masing-masing. Peneliti menggunakan cabang ilmu sistem pendukung keputusan dalam hal ini mengingat cabang imu ini dapat melakukan perangkingan dari sejumlah alternatif berdasarkan kriteria yang telah ditentukan[7]. Dalam penentuan situs travel yang tepat diperlukan suatu metode yang dapat mempertimbangkan seluruh kriteria sehingga konsumen dapat memutuskan situs travel yang tepat[6]. Metode yang digunakan adalah Preference Ranking Organization Method for Enrichment Evaluation (PROMETHE II). Banyak kelebihan yang dimiliki metode tersebut. Hal ini dibuktikan dengan penelitian yang dilakukan [6] tentang faktor penyebab mahasiswa sulit menemukan judul artikel ilmiah. Hasil penelitian menunjukkan bahwa metode tersebut mampu menentukan faktor penyebab mahasiswa sulit menemukan judul karya ilmiah dengan menggunakan metode PROMETHE II. Dalam penelitian ini digunakan 13 (tiga belas) kriteria dan 5 (lima) alternatif. Berdasarkan perhitungan menggunakan metode PROMETHE II, diperoleh hasil perangkingan dengan nilai 0,0896 yaitu faktor Kurang Referensi dan peringkat kedua yaitu faktor Kurang Meminta Saran/Pendapat dengan nilai 0,0255 . Berdasarkan hal tersebut peneliti berharap hasil dari penelitian dapat memberikan rekomendasi berupa informasi kepada konsumen terhadap situs travel yang tepat berdasarkan pilihan konsumen yang didasarkan atas kriteria-kriteria dan alternatif yang telah disepakati. 


\section{LANDASAN TEORI}

\section{A. Sistem Pendukung Keputusan}

Merupakan bagian dari sistem informasi berbasis komputer yang dipakai untuk mendukung pengambilan keputusan dari masalah semi-terstruktur yang spesifik dalam suatu organisasi atau perusahaan [16].

\section{B. PROMETHEE II}

The Preference Ranking Organization METHod for Enrichment of Evaluations II merupakan salah satu dari metode Multi Criteria Decision Making (MCDM) yang menyelesaikan masalah yang berhubungan dengan multikriteria, Perbedaan dengan PROMETHEE adalah pada Metode PROMETHEE memberikan potongan parsial dari alternatif keputusan, sedangkan Metode PROMETHEE II dapat memperoleh rangking keseluruhan dari alternatifnya [6].

Adapun langkah-langkah Prosedural dalam Metode PROMETHEE II yaitu :

1) Menghitung Nilai Preferensi

Menghitung Nilai Preferensi dengan menggunakan persamaan sebagai berikut :

$$
H(d) \quad \begin{cases}0 & \text { jika d }=0 \\ 0 & \text { jika d } \leq 0 \\ 1 & \text { jika d } \geq 0\end{cases}
$$

Keterangan :

$\mathrm{H}(\mathrm{d})$ : fungsi selisih kriteria antar alternatif

$\mathrm{d} \quad$ : selisih nilai kriteria $\{\mathrm{d}=\mathrm{f}(\mathrm{a})-\mathrm{f}(\mathrm{b})\}$

2) Menghitung indeks Preferensi

Hasil dari perhitungan nilai preferensi kemudian akan dihitung kembali untuk mendapatkan indeks preferensi. Rumus yang digunakan adalah :

$$
\varphi(a, b)=\sum_{n-1}^{n} \pi P i(a, b): \forall a, b \in A
$$

3) Menentukan PROMETHEE I

a. Menghitung Leaving flow

Rumus :

$$
\Phi^{+}(a)=\frac{1}{n-1} \sum_{n=k} \varphi(a, x)
$$

b. Menghitung Enteering flow

Rumus :

$$
\Phi^{-}(a)=\frac{1}{n-1} \sum_{n=k} \varphi(a, x)
$$

\section{4) Menentukan PROMETHEE II}

Pada PROMETHEE II yang merupakan perhitungan akhir dalam metode PROMETHEE didapat dengan menghitung Net flow dengan rumus :

$\Phi(a)=\Phi^{+}(a)-\Phi^{-}(a)$

\section{Metode Penelitian}

Penelitian ini dilakukan di STIKOM Tunas Bangsa dengan lokasi penelitian di kota pematangsiantar. Metode yang digunakan pada penelitian ini adalah Preference Ranking Organization Methods for Enrichment Evaluation (PROMETHEE II). Data diperoleh dengan cara wawancara dan memberikan angket secara random kepada 250 pengguna situs travel secara acak. Adapun krieria penilaian yang digunakan seperti: penilaian harga (C1), Pelayanan (C2), Interface (C3), Keamanan (C4), Promosi (C5) , Sistem Pembayaran (C6) dan alternatif situs travel yang digunakan yaitu:: Traveloka (A1), Tiket.com (A2), Trivago (A3), PegiPegi (A4).

\section{ANALISIS DAN PEMBAHASAN}

\section{A. Penentuan Alternatif}

Pada penentuan Alternatif situs travel, penulis menggunakan 4 alternatif seperti yang ditunjukkan pada tabel berikut:

TABEL 1. Alternatif

\begin{tabular}{|c|c|}
\hline Situs Travel & Keterangan \\
\hline Traveloka & $\mathrm{A} 1$ \\
\hline Tiket.com & $\mathrm{A} 2$ \\
\hline Trivago & $\mathrm{A} 3$ \\
\hline Pegi-Pegi & $\mathrm{A} 4$ \\
\hline
\end{tabular}

\section{B. Penentuan Kriteria}

Adapun kriteria yang digunakan pada pemilihan situs travel terbaik menurut konsumen seperti yang ditunjukkan pada tabel berikut:

TABEL 2. Kriteria pemilihan situs travel

\begin{tabular}{|l|l|l|}
\hline Kriteria & Keterangan Kriteria & Ket \\
\hline Kriteria 1 & Harga & $\mathrm{C} 1$ \\
\hline Kriteria 2 & Pelayanan & $\mathrm{C} 2$ \\
\hline Kriteria 3 & Interface & $\mathrm{C} 3$ \\
\hline Kriteria 4 & Keamanan & $\mathrm{C} 4$ \\
\hline Kriteria 5 & Promosi & $\mathrm{C} 5$ \\
\hline Kriteria 6 & Sistem Pembayaran & $\mathrm{C} 6$ \\
\hline
\end{tabular}

C. Penerapan metode PROMETHEE II

Berikut ini data penelitian yang digunakan untuk melakukan perhitungan dengan metode PROMETHEE II sebelumnya data telah direkapitulasi menggunakan software microsoft excel. Berikut data penelitian yang akan diolah menggunakan PROMETHEE II.

Tabel 3. Rating kecocokan setiap alternatif pada setiap kriteria

\begin{tabular}{|c|c|c|c|c|c|c|}
\hline Alternatif & C1 & C2 & C3 & C4 & C5 & C6 \\
\hline Traveloka & 0.83 & 0.80 & 0.86 & 0.78 & 0.80 & 0.85 \\
\hline tiket.com & 0.82 & 0.81 & 0.86 & 0.89 & 0.86 & 0.86 \\
\hline
\end{tabular}




\begin{tabular}{|c|c|c|c|c|c|c|}
\hline Alternatif & C1 & C2 & C3 & C4 & C5 & C6 \\
\hline Trivago & 0.88 & 0.75 & 0.83 & 0.81 & 0.72 & 0.88 \\
\hline pegi pegi & 0.88 & 0.86 & 0.81 & 0.88 & 0.92 & 0.83 \\
\hline
\end{tabular}

Langkah 1 : Menghitung Nilai Preferensi

Nilai kriteria Harga $(\mathrm{C} 1)$

$$
\begin{aligned}
& \mathrm{C} 1(\mathrm{~A} 1, \mathrm{~A} 2) \quad \mathrm{d}=\mathrm{C} 1(\mathrm{~A} 1)-\mathrm{C} 1(\mathrm{~A} 2) \\
& =0.83-0.82 \\
& =0,01 \\
& \mathrm{~d}>0 \text { maka } \mathrm{H}|\mathrm{d}|=1 \\
& \mathrm{C} 1(\mathrm{~A} 2, \mathrm{~A} 1): \mathrm{d}=\mathrm{C} 1(\mathrm{~A} 2)-\mathrm{C} 1(\mathrm{~A} 1) \\
& =0.82-0.83 \\
& =-0.01 \\
& \mathrm{~d}<0 \text { maka } \mathrm{H}|\mathrm{d}|=0 \\
& \mathrm{C} 1(\mathrm{~A} 1, \mathrm{~A} 3): \mathrm{d}=\mathrm{C} 1(\mathrm{~A} 1)-\mathrm{C} 1(\mathrm{~A} 3) \\
& =0.83-0.88 \\
& =-0.04 \\
& \mathrm{~d}<0 \text { maka } \mathrm{H}|\mathrm{d}|=0 \\
& \mathrm{C} 1(\mathrm{~A} 3, \mathrm{~A} 1): \mathrm{d}=\mathrm{C} 1(\mathrm{~A} 3)-\mathrm{C} 1(\mathrm{~A} 1) \\
& =0.88-0.83 \\
& =0.04 \\
& \mathrm{~d}>0 \text { maka } \mathrm{H}|\mathrm{d}|=1 \\
& \mathrm{C} 1(\mathrm{~A} 1, \mathrm{~A} 4): \mathrm{d}=\mathrm{C} 1(\mathrm{~A} 1)-\mathrm{C} 1(\mathrm{~A} 4) \\
& =0.83-0.88 \\
& =-0.04 \\
& \mathrm{~d}<0 \text { maka } \mathrm{H}|\mathrm{d}|=0 \\
& \mathrm{C} 1(\mathrm{~A} 4, \mathrm{~A} 1): \mathrm{d}=\mathrm{C} 1(\mathrm{~A} 4)-\mathrm{C} 1(\mathrm{~A} 1) \\
& =0.88-0.83 \\
& =0.04 \\
& \mathrm{~d}>0 \text { maka } \mathrm{H}|\mathrm{d}|=1 \\
& \mathrm{C} 1(\mathrm{~A} 2, \mathrm{~A} 3): \mathrm{d}=\mathrm{C} 1(\mathrm{~A} 2)-\mathrm{C} 1(\mathrm{~A} 3) \\
& =0.82-0.88 \\
& =-0.05 \\
& \mathrm{~d}<0 \text { maka } \mathrm{H}|\mathrm{d}|=0 \\
& \mathrm{C} 1(\mathrm{~A} 3, \mathrm{~A} 2): \mathrm{d}=\mathrm{C} 1(\mathrm{~A} 3)-\mathrm{C} 1(\mathrm{~A} 2) \\
& =0.88-0.82 \\
& =0.05 \\
& \mathrm{~d}>0 \text { maka } \mathrm{H}|\mathrm{d}|=1 \\
& \mathrm{C} 1(\mathrm{~A} 2, \mathrm{~A} 4): \mathrm{d}=\mathrm{C} 1(\mathrm{~A} 2)-\mathrm{C} 1(\mathrm{~A} 4) \\
& =0.82-0.88 \\
& =-0.05 \\
& \mathrm{~d}<0 \text { maka } \mathrm{H}|\mathrm{d}|=0 \\
& \mathrm{C} 1(\mathrm{~A} 4, \mathrm{~A} 2): \mathrm{d}=\mathrm{C} 1(\mathrm{~A} 4)-\mathrm{C} 1(\mathrm{~A} 2) \\
& =0.88-0.82 \\
& =0.05 \\
& \mathrm{~d}>0 \text { maka } \mathrm{H}|\mathrm{d}|=1 \\
& \mathrm{C} 1(\mathrm{~A} 3, \mathrm{~A} 4): \mathrm{d}=\mathrm{C} 1(\mathrm{~A} 3)-\mathrm{C} 1(\mathrm{~A} 4) \\
& =0.88-0.88 \\
& =0.00 \\
& \mathrm{~d}=0 \text { maka } \mathrm{H}|\mathrm{d}|=0 \\
& \mathrm{C} 1(\mathrm{~A} 4, \mathrm{~A} 3): \mathrm{d}=\mathrm{C} 1(\mathrm{~A} 4)-\mathrm{C} 1(\mathrm{~A} 3) \\
& =0.88-0.88 \\
& =0.00 \\
& \mathrm{~d}=0 \text { maka } \mathrm{H}|\mathrm{d}|=0
\end{aligned}
$$

Setelah menentukan rating kecocokan untuk setiap alternatif pada setiap kriteria, lakukan perhitungan terhadap nilai preferensi. Berikut ini langkah penyelesaiannya.

Nilai kriteria Pelayanan $(\mathrm{C} 2)$

$$
\begin{aligned}
& \mathrm{C} 2(\mathrm{~A} 1, \mathrm{~A} 2) \quad: \mathrm{d}=\mathrm{C} 2(\mathrm{~A} 1)-\mathrm{C} 2(\mathrm{~A} 2) \\
& =0.80-0.81 \\
& =-0,01 \\
& \mathrm{~d}>0 \text { maka } \mathrm{H}|\mathrm{d}|=1 \\
& \mathrm{C} 2(\mathrm{~A} 2, \mathrm{~A} 1): \mathrm{d}=\mathrm{C} 2(\mathrm{~A} 2)-\mathrm{C} 1(\mathrm{~A} 1) \\
& =0.81-0.80 \\
& =-0.01 \\
& \mathrm{~d}<0 \text { maka } \mathrm{H}|\mathrm{d}|=0 \\
& \mathrm{C} 2(\mathrm{~A} 1, \mathrm{~A} 3): \mathrm{d}=\mathrm{C} 2(\mathrm{~A} 1)-\mathrm{C} 2(\mathrm{~A} 3) \\
& =0.80-0.75 \\
& =0.05 \\
& \mathrm{~d}>0 \text { maka } \mathrm{H}|\mathrm{d}|=1 \\
& \mathrm{C} 2(\mathrm{~A} 3, \mathrm{~A} 1): \mathrm{d}=\mathrm{C} 2(\mathrm{~A} 3)-\mathrm{C} 2(\mathrm{~A} 1) \\
& =0.75-0.80 \\
& =-0.05 \\
& \mathrm{~d}<0 \text { maka } \mathrm{H}|\mathrm{d}|=0 \\
& \mathrm{C} 2(\mathrm{~A} 1, \mathrm{~A} 4): \mathrm{d}=\mathrm{C} 2(\mathrm{~A} 1)-\mathrm{C} 2(\mathrm{~A} 4) \\
& =0.80-0.86 \\
& =-0.06 \\
& \mathrm{~d}<0 \text { maka } \mathrm{H}|\mathrm{d}|=0 \\
& \mathrm{C} 2(\mathrm{~A} 4, \mathrm{~A} 1) \quad \mathrm{d}=\mathrm{C} 2(\mathrm{~A} 4)-\mathrm{C} 2(\mathrm{~A} 1) \\
& =0.86-0.80 \\
& =0.06 \\
& \mathrm{~d}>0 \text { maka } \mathrm{H}|\mathrm{d}|=1 \\
& \mathrm{C} 2(\mathrm{~A} 2, \mathrm{~A} 3): \mathrm{d}=\mathrm{C} 2(\mathrm{~A} 2)-\mathrm{C} 2(\mathrm{~A} 3) \\
& =0.81-0.75 \\
& =0.06 \\
& \mathrm{~d}>0 \text { maka } \mathrm{H}|\mathrm{d}|=1 \\
& \text { C2(A3,A2) : d = C2(A3)-C2(A2) } \\
& =0.75-0.81 \\
& =-0.06 \\
& \mathrm{~d}<0 \text { maka } \mathrm{H}|\mathrm{d}|=0 \\
& \mathrm{C} 2(\mathrm{~A} 2, \mathrm{~A} 4): \mathrm{d}=\mathrm{C} 2(\mathrm{~A} 2)-\mathrm{C} 2(\mathrm{~A} 4) \\
& =0.81-0.86 \\
& =-0.05 \\
& \mathrm{~d}<0 \text { maka } \mathrm{H}|\mathrm{d}|=0
\end{aligned}
$$

Nilai kriteria Interface $(\mathrm{C} 3)$

$$
\mathrm{C} 3(\mathrm{~A} 1, \mathrm{~A} 2) \quad: \mathrm{d}=\mathrm{C} 3(\mathrm{~A} 1)-\mathrm{C} 3(\mathrm{~A} 2)
$$


$=0.86-0.86$

$=0.00$

$\mathrm{d}=0$ maka $\mathrm{H}|\mathrm{d}|=0$

$\mathrm{C} 3(\mathrm{~A} 2, \mathrm{~A} 1): \mathrm{d}=\mathrm{C} 3(\mathrm{~A} 2)-\mathrm{C} 3(\mathrm{~A} 1)$

$=0.86-0.86$

$=0.00$

$\mathrm{d}=0$ maka $\mathrm{H}|\mathrm{d}|=0$

$\mathrm{C} 3(\mathrm{~A} 1, \mathrm{~A} 3) \quad \mathrm{d}=\mathrm{C} 3(\mathrm{~A} 1)-\mathrm{C} 3(\mathrm{~A} 3)$

$=0.86-0.83$

$=0.03$

$\mathrm{d}>0$ maka $\mathrm{H}|\mathrm{d}|=1$

$\mathrm{C} 3(\mathrm{~A} 3, \mathrm{~A} 1) \quad \mathrm{d}=\mathrm{C} 3(\mathrm{~A} 3)-\mathrm{C} 3(\mathrm{~A} 1)$

$=0.83-0.86$

$=-0.03$

$\mathrm{d}<0$ maka $\mathrm{H}|\mathrm{d}|=0$

C3(A1,A4) : d = C3(A1)-C3(A4)

$=0.86-0.81$

$=0.06$

$\mathrm{d}>0$ maka $\mathrm{H}|\mathrm{d}|=1$

$\mathrm{C} 3(\mathrm{~A} 4, \mathrm{~A} 1): \mathrm{d}=\mathrm{C} 3(\mathrm{~A} 4)-\mathrm{C} 3(\mathrm{~A} 1)$

$=0.81-0.86$

$=-0.06$

$\mathrm{d}<0$ maka $\mathrm{H}|\mathrm{d}|=0$

C3(A2,A3) : d = C3(A2)-C3(A3)

$=0.86-0.83$

$=0.02$

$\mathrm{d}>0$ maka $\mathrm{H}|\mathrm{d}|=1$

$\mathrm{C} 3(\mathrm{~A} 3, \mathrm{~A} 2): \mathrm{d}=\mathrm{C} 3(\mathrm{~A} 3)-\mathrm{C} 2(\mathrm{~A} 2)$

$=0.83-0.86$

$=-0.02$

$\mathrm{d}<0$ maka $\mathrm{H}|\mathrm{d}|=0$

$\mathrm{C} 3(\mathrm{~A} 2, \mathrm{~A} 4): \mathrm{d}=\mathrm{C} 3(\mathrm{~A} 2)-\mathrm{C} 3(\mathrm{~A} 4)$

$=0.86-0.81$

$=0.05$

$\mathrm{d}>0$ maka $\mathrm{H}|\mathrm{d}|=1$

$\mathrm{C} 3(\mathrm{~A} 4, \mathrm{~A} 2): \mathrm{d}=\mathrm{C} 3(\mathrm{~A} 4)-\mathrm{C} 3(\mathrm{~A} 2)$

$=0.81-0.86$

$=-0.05$

$\mathrm{d}<0$ maka $\mathrm{H}|\mathrm{d}|=0$

$\mathrm{C} 3(\mathrm{~A} 3, \mathrm{~A} 4): \mathrm{d}=\mathrm{C} 3(\mathrm{~A} 3)-\mathrm{C} 3(\mathrm{~A} 4)$

$=0.83-0.81$

$=0.03$

$\mathrm{d}>0$ maka $\mathrm{H}|\mathrm{d}|=1$

C3(A4,A3) : d = C3(A4)-C3(A3)

$=0.81-0.83$

$=-0.03$

$\mathrm{d}<0$ maka $\mathrm{H}|\mathrm{d}|=0$

Nilai kriteria Keamanan (C4)

$\begin{aligned} \mathrm{C} 4(\mathrm{~A} 1, \mathrm{~A} 2) \quad \mathrm{d} & =\mathrm{C} 4(\mathrm{~A} 1)-\mathrm{C} 4(\mathrm{~A} 2) \\ & =0.78-0.89 \\ & =-0.12 \\ \mathrm{~d} & <0 \text { maka } \mathrm{H}|\mathrm{d}|=0 \\ \mathrm{C} 4(\mathrm{~A} 2, \mathrm{~A} 1) \quad: \mathrm{d} & =\mathrm{C} 4(\mathrm{~A} 2)-\mathrm{C} 4(\mathrm{~A} 1) \\ & =0.89-0.78\end{aligned}$
$=0.12$

$\mathrm{d}>0$ maka $\mathrm{H}|\mathrm{d}|=1$

$\mathrm{C} 4(\mathrm{~A} 1, \mathrm{~A} 3) \quad \mathrm{d}=\mathrm{C} 4(\mathrm{~A} 1)-\mathrm{C} 4(\mathrm{~A} 3)$

$=0.78-0.81$

$=-0.04$

$\mathrm{d}<0$ maka $\mathrm{H}|\mathrm{d}|=0$

$\mathrm{C} 4(\mathrm{~A} 3, \mathrm{~A} 1): \mathrm{d}=\mathrm{C} 4(\mathrm{~A} 3)-\mathrm{C} 4(\mathrm{~A} 1)$

$=0.81-0.78$

$=0.04$

$\mathrm{d}>0$ maka $\mathrm{H}|\mathrm{d}|=1$

C4(A1,A4) : d = C4(A1)-C4(A4)

$=0.78-0.88$

$=-0.10$

$\mathrm{d}<0$ maka $\mathrm{H}|\mathrm{d}|=0$

$\mathrm{C} 4(\mathrm{~A} 4, \mathrm{~A} 1) \quad: \mathrm{d}=\mathrm{C} 4(\mathrm{~A} 4)-\mathrm{C} 4(\mathrm{~A} 1)$

$=0.88-0.78$

$=0.10$

$\mathrm{d}>0$ maka $\mathrm{H}|\mathrm{d}|=1$

$\mathrm{C} 4(\mathrm{~A} 2, \mathrm{~A} 3) \quad: \mathrm{d}=\mathrm{C} 4(\mathrm{~A} 2)-\mathrm{C} 4(\mathrm{~A} 3)$

$=0.89-0.81$

$=0.08$

$\mathrm{d}>0$ maka $\mathrm{H}|\mathrm{d}|=1$

$\mathrm{C} 4(\mathrm{~A} 3, \mathrm{~A} 2) \quad: \mathrm{d}=\mathrm{C} 4(\mathrm{~A} 3)-\mathrm{C} 4(\mathrm{~A} 2)$

$=0.81-0.89$

$=-0.08$

$\mathrm{d}<0$ maka $\mathrm{H}|\mathrm{d}|=0$

$\mathrm{C} 4(\mathrm{~A} 2, \mathrm{~A} 4): \mathrm{d}=\mathrm{C} 4(\mathrm{~A} 2)-\mathrm{C} 4(\mathrm{~A} 4)$

$=0.89-0.88$

$=0.02$

$\mathrm{d}>0$ maka $\mathrm{H}|\mathrm{d}|=1$

$\mathrm{C} 4(\mathrm{~A} 4, \mathrm{~A} 2): \mathrm{d}=\mathrm{C} 4(\mathrm{~A} 4)-\mathrm{C} 4(\mathrm{~A} 2)$

$=0.88-0.89$

$=-0.02$

$\mathrm{d}<0$ maka $\mathrm{H}|\mathrm{d}|=0$

$\mathrm{C} 4(\mathrm{~A} 3, \mathrm{~A} 4) \quad: \mathrm{d}=\mathrm{C} 4(\mathrm{~A} 3)-\mathrm{C} 4(\mathrm{~A} 4)$

$=0.81-0.88$

$=-0.06$

$\mathrm{d}<0$ maka $\mathrm{H}|\mathrm{d}|=0$

$\mathrm{C} 4(\mathrm{~A} 4, \mathrm{~A} 3): \mathrm{d}=\mathrm{C} 4(\mathrm{~A} 4)-\mathrm{C} 4(\mathrm{~A} 3)$

$=0.88-0.81$

$=0.06$

$\mathrm{d}>0$ maka $\mathrm{H}|\mathrm{d}|=1$

Nilai kriteria Promosi (C5)

$$
\begin{aligned}
& \mathrm{C} 5(\mathrm{~A} 1, \mathrm{~A} 2) \quad: \mathrm{d}=\mathrm{C} 5(\mathrm{~A} 1)-\mathrm{C} 5(\mathrm{~A} 2) \\
&=0.80-0.86 \\
&=-0.05 \\
& \mathrm{~d}<0 \text { maka } \mathrm{H}|\mathrm{d}|=0 \\
& \mathrm{C} 5(\mathrm{~A} 2, \mathrm{~A} 1) \quad: \mathrm{d}=\mathrm{C} 5(\mathrm{~A} 2)-\mathrm{C} 5(\mathrm{~A} 1) \\
&=0.86-0.80 \\
&=0.06 \\
& \mathrm{~d}>0 \text { maka } \mathrm{H}|\mathrm{d}|=1 \\
& \mathrm{C} 5(\mathrm{~A} 1, \mathrm{~A} 3) \quad: \mathrm{d}=\mathrm{C} 5(\mathrm{~A} 1)-\mathrm{C} 5(\mathrm{~A} 3) \\
&=0.80-0.72 \\
&=0.08
\end{aligned}
$$




$$
\begin{aligned}
& \mathrm{d}>0 \text { maka } \mathrm{H}|\mathrm{d}|=1 \\
& \mathrm{C} 5(\mathrm{~A} 3, \mathrm{~A} 1) \quad: \mathrm{d}=\mathrm{C} 5(\mathrm{~A} 3)-\mathrm{C} 5(\mathrm{~A} 1) \\
& =0.72-0.80 \\
& =-0.08 \\
& \mathrm{~d}<0 \text { maka } \mathrm{H}|\mathrm{d}|=0 \\
& \mathrm{C} 5(\mathrm{~A} 1, \mathrm{~A} 4) \quad: \mathrm{d}=\mathrm{C} 5(\mathrm{~A} 1)-\mathrm{C} 5(\mathrm{~A} 4) \\
& =0.80-0.92 \\
& =-0.11 \\
& \mathrm{~d}<0 \text { maka } \mathrm{H}|\mathrm{d}|=0 \\
& \mathrm{C} 5(\mathrm{~A} 4, \mathrm{~A} 1): \mathrm{d}=\mathrm{C} 5(\mathrm{~A} 4)-\mathrm{C} 5(\mathrm{~A} 1) \\
& =0.92-0.80 \\
& =0.11 \\
& \mathrm{~d}>0 \text { maka } \mathrm{H}|\mathrm{d}|=1 \\
& \mathrm{C} 5(\mathrm{~A} 2, \mathrm{~A} 3) \quad \mathrm{d}=\mathrm{C} 5(\mathrm{~A} 2)-\mathrm{C} 5(\mathrm{~A} 3) \\
& =0.86-0.72 \\
& =0.14 \\
& \mathrm{~d}>0 \text { maka } \mathrm{H}|\mathrm{d}|=1 \\
& \mathrm{C} 5(\mathrm{~A} 3, \mathrm{~A} 2) \quad \mathrm{d}=\mathrm{C} 5(\mathrm{~A} 3)-\mathrm{C} 5(\mathrm{~A} 2) \\
& =0.72-0.86 \\
& =-0.14 \\
& \mathrm{~d}<0 \text { maka } \mathrm{H}|\mathrm{d}|=0 \\
& \mathrm{C} 5(\mathrm{~A} 2, \mathrm{~A} 4): \mathrm{d}=\mathrm{C} 5(\mathrm{~A} 2)-\mathrm{C} 5(\mathrm{~A} 4) \\
& =0.86-0.92 \\
& =-0.06 \\
& \mathrm{~d}<0 \text { maka } \mathrm{H}|\mathrm{d}|=0 \\
& \mathrm{C} 5(\mathrm{~A} 4, \mathrm{~A} 2) \quad \mathrm{d}=\mathrm{C} \text { (A4)-C5(A2) } \\
& =0.92-0.86 \\
& =0.06 \\
& \mathrm{~d}>0 \text { maka } \mathrm{H}|\mathrm{d}|=1 \\
& \mathrm{C} 5(\mathrm{~A} 3, \mathrm{~A} 4) \quad \mathrm{d}=\mathrm{C} 5(\mathrm{~A} 3)-\mathrm{C} 5(\mathrm{~A} 4) \\
& =0.72-0.92 \\
& =-0.20 \\
& \mathrm{~d}<0 \text { maka } \mathrm{H}|\mathrm{d}|=0 \\
& \mathrm{C} 5(\mathrm{~A} 4, \mathrm{~A} 3) \quad \mathrm{d}=\mathrm{C} 5(\mathrm{~A} 4)-\mathrm{C} 5(\mathrm{~A} 3) \\
& =0.92-0.72 \\
& =0.20 \\
& \mathrm{~d}>0 \text { maka } \mathrm{H}|\mathrm{d}|=1
\end{aligned}
$$

Nilai kriteria Sistem Pembayaran (C6)

$$
\begin{aligned}
& \mathrm{C} 6(\mathrm{~A} 1, \mathrm{~A} 2) \quad: \mathrm{d}=\mathrm{C} 6(\mathrm{~A} 1)-\mathrm{C} 6(\mathrm{~A} 2) \\
& =0.85-0.86 \\
& =0.00 \\
& \mathrm{~d}=0 \text { maka } \mathrm{H}|\mathrm{d}|=0 \\
& \text { C6(A2,A1) }: \mathrm{d}=\mathrm{C} 6(\mathrm{~A} 2)-\mathrm{C} 6(\mathrm{~A} 1) \\
& =0.86-0.85 \\
& =0.00 \\
& \mathrm{~d}=0 \text { maka } \mathrm{H}|\mathrm{d}|=0 \\
& \text { C6(A1,A3) : } d=\text { C6(A1)-C6(A3) } \\
& =0.85-0.88 \\
& =-0.02 \\
& \mathrm{~d}<0 \text { maka } \mathrm{H}|\mathrm{d}|=0 \\
& \text { C6(A3,A1) }: \mathrm{d}=\mathrm{C} 6(\mathrm{~A} 3)-\mathrm{C} 6(\mathrm{~A} 1) \\
& =0.88-0.85 \\
& =0.02 \\
& \mathrm{~d}>0 \text { maka } \mathrm{H}|\mathrm{d}|=1
\end{aligned}
$$

$$
\begin{aligned}
& \text { C6(A1,A4) : d = C6(A1)-C6(A4) } \\
& =0.85-0.83 \\
& =0.02 \\
& \mathrm{~d}>0 \text { maka } \mathrm{H}|\mathrm{d}|=1 \\
& \text { C6(A4,A1) }: \mathrm{d}=\mathrm{C} 6(\mathrm{~A} 4)-\mathrm{C} 6(\mathrm{~A} 1) \\
& =0.83-0.85 \\
& =-0.02 \\
& \mathrm{~d}<0 \text { maka } \mathrm{H}|\mathrm{d}|=0 \\
& \text { C6(A2,A3) : d = C6(A2)-C6(A3) } \\
& =0.86-0.88 \\
& =-0.02 \\
& \mathrm{~d}<0 \text { maka } \mathrm{H}|\mathrm{d}|=0 \\
& \text { C6(A3,A2) : d = C6(A3)-C6(A2) } \\
& =0.88-0.86 \\
& =0.02 \\
& \mathrm{~d}>0 \text { maka } \mathrm{H}|\mathrm{d}|=1 \\
& \text { C6(A2,A4) : d = C6(A2)-C6(A4) } \\
& =0.86-0.83 \\
& =0.02 \\
& \mathrm{~d}>0 \text { maka } \mathrm{H}|\mathrm{d}|=1 \\
& \text { C6(A4,A2) : d = C6(A4)-C6(A2) } \\
& =0.83-0.86 \\
& =-0.02 \\
& \mathrm{~d}<0 \text { maka } \mathrm{H}|\mathrm{d}|=0 \\
& \text { C6(A3,A4) : d = C6(A3)-C6(A4) } \\
& =0.88-0.83 \\
& =0.04 \\
& \mathrm{~d}>0 \text { maka } \mathrm{H}|\mathrm{d}|=1 \\
& \text { C6(A4,A3) : d = C6(A4)-C6(A3) } \\
& =0.83-0.88 \\
& =-0.04 \\
& \mathrm{~d}<0 \text { maka } \mathrm{H}|\mathrm{d}|=0
\end{aligned}
$$

Sehingga diperoleh hasil lengkap Nilai Preferensi

TABEL 4. Tabel Preferensi

\begin{tabular}{|c|c|c|c|c|c|c|}
\hline$(\mathrm{d})$ & $\mathrm{C} 1$ & $\mathrm{C} 2$ & $\mathrm{C} 3$ & $\mathrm{C} 4$ & $\mathrm{C} 5$ & $\mathrm{C} 6$ \\
\hline (A1,A2) & 1 & 0 & 0 & 0 & 0 & 0 \\
\hline (A2,A1) & 0 & 1 & 0 & 1 & 1 & 0 \\
\hline (A1,A3) & 0 & 1 & 1 & 0 & 1 & 0 \\
\hline (A3,A1) & 1 & 0 & 0 & 1 & 0 & 1 \\
\hline (A1,A4) & 0 & 0 & 1 & 0 & 0 & 1 \\
\hline (A4,A1) & 1 & 1 & 0 & 1 & 1 & 0 \\
\hline (A2,A3) & 0 & 1 & 1 & 1 & 1 & 0 \\
\hline (A3,A2) & 1 & 0 & 0 & 0 & 0 & 1 \\
\hline (A2,A4) & 0 & 0 & 1 & 1 & 0 & 1 \\
\hline (A4,A2) & 1 & 1 & 0 & 0 & 1 & 0 \\
\hline (A3,A4) & 0 & 0 & 1 & 0 & 0 & 1 \\
\hline (A4,A3) & 0 & 1 & 0 & 1 & 1 & 0 \\
\hline
\end{tabular}

Langkah 2 : Menghitung Indeks Preferensi Alternatif Pasangan (A1,A2)

$(\mathrm{A} 1, \mathrm{~A} 2)=(1+0+0+0+0+0)=0.17$ Alternatif Pasangan (A2,A1)

$(\mathrm{A} 2, \mathrm{~A} 1)=(0+1+0+1+1+0)=0.50$ 
Alternatif Pasangan (A1,A3)

$(\mathrm{A} 1, \mathrm{~A} 3)=(0+1+1+0+1+0)=0.50$

Alternatif Pasangan (A3,A1)

$(\mathrm{A} 3, \mathrm{~A} 1)=(1+0+0+1+0+1)=0.50$

Alternatif Pasangan (A1,A4)

$(\mathrm{A} 1, \mathrm{~A} 4)=(0+0+1+0+0+1)=0.33$

Alternatif Pasangan (A4,A1)

$(\mathrm{A} 4, \mathrm{~A} 1)=(1+1+0+1+1+0)=0.67$

Alternatif Pasangan (A2,A3)

$(\mathrm{A} 2, \mathrm{~A} 3)=(0+1+1+1+1+0)=0.67$

Alternatif Pasangan (A3,A2)

$(\mathrm{A} 3, \mathrm{~A} 2)=(1+0+0+0+0+1)=0.33$

Alternatif Pasangan (A2,A4)

$(\mathrm{A} 2, \mathrm{~A} 4)=(0+0+1+1+0+1)=0.50$

Alternatif Pasangan (A4,A2)

$(\mathrm{A} 4, \mathrm{~A} 2)=(1+1+0+0+1+0)=0.50$

Alternatif Pasangan (A3,A4)

$(\mathrm{A} 3, \mathrm{~A} 4)=(0+0+1+0+0+1)=0.33$

Alternatif Pasangan (A4,A3)

$(\mathrm{A} 4, \mathrm{~A} 3)=(0+1+0+1+1+0)=0.50$

Berikut Ini hasil nilai indeks preferensi yang ditunjukkan pada tabel berikut :

TABEL 5. Nilai Indeks Preferensi

\begin{tabular}{|c|c|c|c|c|}
\hline & A1 & A2 & A3 & A4 \\
\hline A1 & - & 0.17 & 0.50 & 0.33 \\
\hline A2 & 0.50 & - & 0.67 & 0.50 \\
\hline A3 & 0.50 & 0.33 & - & 0.33 \\
\hline A4 & 0.67 & 0.50 & 0.50 & - \\
\hline
\end{tabular}

\section{Langkah 3 : Menghitung PROMETHEE I}

I. Menghitung Leaving Flow

$\mathrm{A} 1=1 /(6-1)(0.17+0.50+0.33)=0.20$

$\mathrm{A} 2=1 /(6-1)(0.50+0.67+0.50)=0.33$

$\mathrm{A} 3=1 /(6-1)(0.50+0.33+0.33)=0.23$

$\mathrm{A} 4=1 /(6-1)(0.67+0.50+0.50)=0.33$

II. Menghitung Entering Flow

$\mathrm{A} 1=1 /(6-1)(0.50+0.50+0.67)=0.33$

$\mathrm{A} 2=1 /(6-1)(0,17+0.33+0.50)=0.20$

$\mathrm{A} 3=1 /(6-1)(0.50+0.67+0.50)=0.33$

$\mathrm{A} 4=1 /(6-1)(0.33+0.50+0.33)=0.23$

TABEL 6. PROMETHEE I

\begin{tabular}{|c|c|c|}
\hline & leaving flow & entering flow \\
\hline Traveloka & 0.20 & 0.33 \\
\hline Tiket.com & 0.33 & 0.20 \\
\hline Trivago & 0.23 & 0.33 \\
\hline Prgi-pegi & 0.33 & 0.23 \\
\hline
\end{tabular}

Langkah 4 : Menghitung PROMETHEE II

PROMETHEE II merupakan perhitungan akhir dala metode
PROMETHEE didapan dengan menghitung Net flow :

$$
\begin{aligned}
& A=0.20-0.33=-0.13 \\
& B=0.33-0.20=0.13 \\
& C=0.23-0.33=-0.10 \\
& D=0.33-0.23=0.10
\end{aligned}
$$

TABEL.7 PROMETHEE II

\begin{tabular}{|c|c|c|}
\hline & Net flow & Rangking \\
\hline Traveloka & -0.13 & 4 \\
\hline Tiket.com & 0.13 & 1 \\
\hline Trivago & -0.10 & 3 \\
\hline Pegi-Pegi & 0.10 & 2 \\
\hline
\end{tabular}

Berdasarkan Netflow dari tabel diatas maka dapat diperoleh ranking dari masing masing alternatif situs travel. Alternatif dengan net flow yang paling besar merupakan alternatif dengan ranking teratas seperti terlihat pada tabel berikut :

TABEL.8 Hasil Akhir

\begin{tabular}{|c|c|c|}
\hline & Net flow & Rangking \\
\hline Tiket.com & 0.13 & 1 \\
\hline Pegi-Pegi & 0.10 & 2 \\
\hline Trivago & -0.10 & 3 \\
\hline Traveloka & -0.13 & 4 \\
\hline
\end{tabular}

\section{KESIMPULAN}

Berdasarkan penelitian tersebut dapat dijelaskan bahwa metode PROMETHEE II dapat diterapkan pada pemilihan situs travel yang tepat berdasarkan konsumen. Hasil penelitian menunjukkan dari kriteria penilaian yang digunakan (penilaian harga, Pelayanan, Interface, Keamanan, Promosi, Sistem Pembayaran) dan alternatif situs travel yang diteliti (Traveloka, Tiket.com, Trivago, Pegi-Pegi) menyebutkan bahwa situs travel dengan alternatif Tiket.com (A2) (net flow $=0.13$ ) sebagai alternatif pertama dan alternatif pegi-pegi (A4) (net flow=0.10) sebagai alternatif kedua.

\section{DAFTAR PUSTAKA}

[1] A. P. Windarto, "Implementation of Data Mining on Rice Imports by Major Country of Origin Using Algorithm Using KMeans Clustering Method," Int. J. Art if. Intell. Res., vol. 1, no. 2, pp. 26-33, 2017.

[2] M. G. Sadewo, A. P. Windarto, and D. Hartama, "PENERAPAN DATAMINING PADA POPULASI DAGING AYAM RAS PEDAGING DI INDONESIA BERDASARKAN PROVINSI MENGGUNAKAN K-MEANS CLUSTERING," InfoTekJar (Jurnal Nas. Inform. dan Teknol. Jaringan), vol. 2, no. 1, pp. 6067, 2017.

[3] A. P. Windarto, "Penerapan Data Mining Pada Ekspor BuahBuahan Menurut Negara Tujuan Menggunakan K-Means Clustering," Techno.COM, vol. 16, no. 4, pp. 348-357, 2017.

[4] Sudirman, A. P. Windarto, and A. Wanto, "Data mining tools | rapidminer: K-means method on clustering of rice crops by province as efforts to stabilize food crops in Indonesia," IOP Conf. Ser. Mater. Sci. Eng., vol. 420, p. 12089, 2018. 
[5] B. Supriyadi, A. P. Windarto, T. Soemartono, and Mungad, "Classification of natural disaster prone areas in Indonesia using K-means," Int. J. Grid Distrib. Comput., vol. 11, no. 8, pp. 8798, 2018.

[6] F. Adelia, D. Wahyuli, T. Imanda, and A. P. Windato, "Analisis Promethee II Pada Faktor Penyebab Mahasiswa Sulit Menemukan Judul Artikel Ilmiah," Jurnal Ilmiah KOMPUTASI, vol. 17, no. 2, pp. 131-135, 2018 .

[7] S. Sundari, A. Wanto, Saifullah, and I. Gunawan, "Sistem Pendukung Keputusan Dengan Menggunakan Metode Electre Dalam Merekomendasikan Dosen Berprestasi Bidang Ilmu Komputer (Study Kasus di AMIK \& STIKOM Tunas Bangsa)," in Seminar Nasional Multi Disiplin Ilmu, 2017, pp. 1-6.

[8] A. Putrama and A. P. Windarto, "Analisis dalam menentukan produk bri syariah terbaik berdasarkan dana pihak ketiga menggunakan ahp,” CESS (Journal Comput. Eng. Syst. Sci., vol. 3, no. 1, pp. 60-64, 2018.

[9] A. P. WINDARTO, "Implementasi metode topsis dan saw dalam memberikan reward pelanggan," Kumpul. J. Ilmu Komput., vol. 4, no. 1, pp. 88-101, 2017.

[10] P. P. P. A. N. W. F. I. R. H. Zer and A. P. Windarto, "Analisis Pemilihan Rekomendasi Produk Terbaik Prudential Berdasarkan Jenis Asuransi Jiwa Berjangka Untuk Kecelakaan Menggunakan Metode Analytic Hierarchy Process ( Ahp )," CESS (Journal Comput. Eng. Syst. Sci., vol. 3, no. 1, pp. 78-82, 2018.

11] D. R. Sari, A. P. Windarto, D. Hartama, and S. Solikhun, "Sistem Pendukung Keputusan untuk Rekomendasi Kelulusan Sidang Skripsi Menggunakan Metode AHP-TOPSIS," J. Teknol. dan Sist. Komput., vol. 6, no. 1, p. 1, 2018.

[12] A. P. W. Budiharjo and A. Muhammad, "Comparison of Weighted Sum Model and Multi Attribute Decision Making Weighted Product Methods in Selecting the Best Elementary School in Indonesia," Int. J. Softw. Eng. Its Appl., vol. 11, no. 4, pp. 69-90, 2017.

[13] A. Wanto, "Analisis Penerapan Fuzzy Inference System (FIS) Dengan Metode Mamdani Pada Sistem Prediksi Mahasiswa Non Aktif (Studi Kasus : AMIK Tunas Bangsa Pematangsiantar)," in Seminar Nasional Inovasi Dan Teknologi Informasi (SNITI) 3, 2016, vol. 3, pp. 393-400.

[14] T. Imandasari and A. P. Windarto, "Sistem Pendukung Keputusan dalam Merekomendasikan Unit Terbaik di PDAM Tirta Lihou Menggunakan Metode Promethee," J. Teknol. dan Sist. Komput., vol. 5, no. 4, p. 159, 2017.

[15] M. Mohammadi and S. Jafari, "An expert system for recommending suitable ornamental fish addition to an aquarium based on aquarium condition," arXiv Prepr. arXiv1405.1524, vol. 3, no. 2, pp. 1-7, 2014.

[16] A. P. Windarto, M. R. Lubis, and Solikhun, "IMPLEMENTASI JST PADA PREDIKSI TOTAL LABA RUG KOMPREHENSIF BANK UMUM KONVENSIONAL DENGAN BACKPROPAGATION," J. Teknol. Inf. dan Ilmu Komput., vol. 5, no. 4, pp. 411-418, 2018.

[17] A. P. Windarto et al., "MODEL ARSITEKTUR NEURAL NETWORK DENGAN BACKPROPOGATION PADA PREDIKSI TOTAL LABA,” vol. 5, no. 2, pp. 147-158, 2018.

[18] Solikhun, A. P. Windarto, Handrizal, and M.Fauzan, "Jaringan Syaraf Tiruan Dalam Memprediksi Sukuk Negara Ritel Berdasarkan Kelompok Profesi Dengan Backpropagation Dalam Mendorong Laju Pertumbuhan Ekonomi," in Seminar Ilmiah Nasional "Membangun Paradigma Kehidupan Melalui Multidisiplin Ilmu, 2017, pp. 14-31.

[19] A. P. Windarto, L. S. Dewi, and D. Hartama, "Implementation of Artificial Intelligence in Predicting the Value of Indonesian Oil and Gas Exports With BP Algorithm," Int. J. Recent Trends Eng. Res., vol. 3, no. 10, pp. 1-12, 2017.

[20] A. Wanto, A. P. Windarto, D. Hartama, and I. Parlina, "Use of Binary Sigmoid Function And Linear Identity In Artificial Neural Networks For Forecasting Population Density," Int. J. Inf. Syst. Technol., vol. 1, no. 1, pp. 43-54, 2017.
[21] Sumijan, A. P. Windarto, A. Muhammad, and Budiharjo, "Implementation of Neural Networks in Predicting the Understanding Level of Students Subject," Int. J. Softw. Eng. Its Appl., vol. 10, no. 10, pp. 189-204, 2016.

[22] R. Rahim et al., "Enhanced pixel value differencing with cryptography algorithm," in MATEC Web of Conferences 197, 2018, vol. 3011, pp. 1-5.

23] S. R. Ningsih and A. P. Windarto, "Penerapan Metode Promethee II Pada Dosen Penerima Hibah P2M Internal," InfoTekJar (Jurnal Nas. Inform. dan Teknol. Jaringan), vol. 3, no. 1, pp. 20 25,2018 